\title{
Prediktor-korrektor belsőpontos algoritmus az általános lineáris komplementaritási feladatra
}

\section{Predictor-Corrector Interior-Point Algorithm for the General Linear Complementarity Problem}

\author{
Darvay Zsolt, ${ }^{1}$ Füstös Ágnes ${ }^{2}$ \\ ${ }^{1}$ Babeș-Bolyai Tudományegyetem, Matematika és Informatika Kar, Kolozsvár, Románia, \\ darvay@cs.ubbcluj.ro; Erdélyi Múzeum-Egyesület, Matematikai és Informatikai Szakosztály \\ ${ }^{2}$ Babeș-Bolyai Tudományegyetem, Matematika és Informatika Kar, Kolozsvár, Románia, \\ fustosagi@yahoo.com
}

\begin{abstract}
We study a predictor-corrector interior-point algorithm for solving general linear complementarity problems from the implementation point of view. We analyze the method proposed by Illés, Nagy and Terlaky [1] that extends the algorithm published by Potra and Liu [2] to general linear complementarity problems. A new method for determining the step size of the corrector direction is presented. Using the code implemented in the $\mathrm{C}++^{+}$programming language, we can solve large-scale problems based on sufficient matrices.
\end{abstract}

Keywords: interior-point algorithm, general linear complementarity problem, predictor-corrector algorithm, numerical results, sufficient matrix, object-oriented programming.

\section{Összefoglalás}

Prediktor-korrektor általános lineáris komplementaritási feladatra vonatkozó belsőpontos algoritmust vizsgálunk az implementáció szemszögéből nézve. Az Illés, Nagy és Terlaky [1] által megadott módszert elemezzük, amely általános lineáris komplementaritási feladatra terjeszti ki a Potra és Liu [2] által közölt algoritmust. A korrektorirány lépéshosszának meghatározására egy új módszert vezetünk be. A C++ programozási nyelvben implementált kód nagy méretű elégséges mátrixokra alapozott feladatok megoldására is alkalmas.

Kulcsszavak: belsőpontos algoritmus, általános lineáris komplementaritási feladat, prediktor-korrektor módszer, numerikus eredmények, elégséges mátrix, objektumorientált programozás.

\section{Bevezetés}

Lineáris komplementaritási feladatokkal ( $L C P$ ) a gyakorlatban különböző műszaki vagy gazdasági problémák megoldása során találkozhatunk. A feladatot egy M mátrix határozza meg, amely egy lineáris összefüggésben szerepel, de ezenkívül teljesülnie kell egy komplementaritási feltételnek is.

Az LCP NP-teljes feladat, ezért nagyon bonyolult egy hatékony általános megoldást adni rá. Léteznek algoritmusok, amelyek polinom időn belül oldják meg az $L C P$-t, ha az M mátrix pozitív szemidefinit. Ennek kiterjesztéseként bevezették az elégséges mátrix fogalmát, és bebizonyították, hogy ilyen tulajdonságú bemeneti M mátrix esetén is megoldható a feladat polinom időben.

$\mathrm{Az}$ általános LCP (General Linear Complementarity Problem, GLCP) keretében bevezetett algoritmusok el tudják dönteni, hogy a GLCP mátrixa $P_{*}(\kappa)$ tulajdonságú vagy sem (az elégségességgel egyenértékű tulajdonság).

Az Illés Tibor, Nagy Marianna és Terlaky Tamás által bevezetett módszer [1, 3, 4] alapján a különböző belsőpontos algoritmusok beépített ellenőrzések segítségével oldják meg a GLCP-t polinom időben. 
Korábban már implementáltunk egy rövid lépéses belsőpontos algoritmust a GLCP megoldására [5]. Mivel a prediktor-korrektor módszer általában hatékonyabb, a továbbiakban egy ilyen jellegű algoritmus megvalósítását vizsgáljuk.

\section{A lineáris komplementaritási feladat bemutatása}

Az $L C P$ esetén azokat az $x, s \in \mathbb{R}^{n}$ vektorokat keressük, amelyekre:

$$
\left\{\begin{array}{c}
M x+q=s \\
x s=0 \\
x \geq 0, s \geq 0
\end{array}\right.
$$

ahol $q \in \mathbb{R}^{n}, M \in \mathbb{R}^{n \times n}$ és $x s$ a vektorok komponensenkénti szorzatát jelöli.

\section{A $P_{*}(\kappa)$ tulajdonság}

Kojima és társai [6] meghatározásában egy $M \in \mathbb{R}^{n \times n}$ mátrix $P_{*}(\kappa)$ tulajdonságú $(\kappa \geq 0)$, ha bármely $x \in \mathbb{R}^{n}$ esetén teljesül a következő:

$$
(1+4 \kappa) \sum_{i \in J_{+}(x)} x_{i}(M x)_{i}+\sum_{i \in J_{-}(x)} x_{i}(M x)_{i} \geq 0,
$$

ahol $J_{+}(x)=\left\{1 \leq i \leq n: x_{i}(M x)_{i}>0\right\}$ és

$$
J_{-}(x)=\left\{1 \leq i \leq n: x_{i}(M x)_{i}<0\right\} .
$$

Egy $M \in \mathbb{R}^{n \times n}$ mátrix $P_{*}$ tulajdonságú, ha $P_{*}(\kappa)$ tulajdonságú valamely $\kappa \geq 0$ értékre. Megjegyezzük, hogy $\kappa=0$ esetén a pozitív szemidefinit mátrixok osztályát kapjuk vissza.

\section{Lokális $\kappa$ értékek}

Az egyes iterációk prediktor-, illetve korrektorlépéseiben az alábbi függvény segítségével kiszámolunk egy lokális $\kappa$-t $[1,4]$, majd az összes ilyen érték közül kiválasztva a maximumot egy alsó korlátot határozunk meg az M mátrixot jellemző $\kappa$-ra:

$$
\kappa(\Delta x)=-\frac{1}{4} \frac{\Delta x^{T} M \Delta x}{\sum_{i \in \mathcal{J}_{+}}(\Delta x) \Delta x_{i}(M \Delta x)_{i}} .
$$

\section{A környezet fogalma}

\section{Legyen $\gamma \in(0,1)$ és}

$$
\mathcal{F}^{0}:=\left\{(x, s) \in \mathbb{R}^{n} \times \mathbb{R}^{n}:-M x+s=q, x, s>0\right\} .
$$

Potra és Liu [2] a környezetet a következőképpen definiálta:

$$
D(\gamma):=\left\{(x, s) \in \mathcal{F}^{0}: x s \geq \gamma \frac{x^{T} s}{n} e\right\},
$$

ahol $e$ az 1-esekből álló $n$ dimenziós vektor.

\section{A Newton-módszer}

$\mathrm{Az}$ algoritmus egy kezdeti $\left(x_{0}, s_{0}\right)$ pontból indul, és a prediktor-, illetve korrektorirányok kiszámolása érdekében az alábbi Newton-rendszert oldjuk meg:

$$
\left\{\begin{array}{c}
-M \Delta x+\Delta s=-r_{q}, \\
s \Delta x+x \Delta s=a,
\end{array}\right.
$$

ahol $r_{q}=M x+q-s$ a megengedettség megőrzése érdekében került bevezetésre.

Megjegyezzük, hogy a prediktorlépésben $a=-x S$, illetve a korrektorlépésben $a=\mu e-x s$ lesz. Ugyanakkor az algoritmus folyamán az alábbi jelöléseket is használjuk:

$x(\alpha)=x+\alpha \Delta x, s(\alpha)=s+\alpha \Delta s$, ahol $\alpha>0$ a lépéshosszt adja meg.

\section{Az algoritmus}

Az Illés, Nagy és Terlaky [1] által bevezetett algoritmusból kiindulva a GLCP-t megoldó prediktor-korrektor algoritmust a következőképpen adjuk meg:

\section{Bemeneti paraméterek:}

$\tilde{\kappa}>0$ felső korlát a $\kappa$ számára;

$\varepsilon>0$ pontossági paraméter;

$\gamma \in(0,1)$ környezetre vonatkozó paraméter;

$\left(x_{0}, s_{0}\right) \in D(\gamma)$ kezdőpont;

$\sigma \in(0,1]$ a $\mu$ csökkentését szabályozó paraméter;

$\rho \in(0,1)$ a lépéshossz csökkentésére vonatkozó paraméter;

$\beta, \beta_{\text {max }}>0$ a korrektorlépéshossz pontosságára vonatkozó paraméterek;

\section{Kimenet:}

az $(x, s)$ vektorpár - az LCP megoldása - vagy egy üzenet arra vonatkozóan, hogy nem teljesül a $P_{*}(\kappa)$ tulajdonság.

\section{BEGIN}

$x:=x_{0} ; s:=s_{0} ; \mu:=\sigma \frac{\left(x_{0}\right)^{T} s_{0}}{n} ; \kappa:=0 ;$

$r_{q}=M x+q-s ; \quad \alpha_{p}^{*}(\kappa)=\frac{2 \sqrt{(1-\gamma) \gamma}}{(1+4 \kappa) n+2} ;$

while $\frac{x^{T} s}{1+x_{0}^{T} s_{0}}>\varepsilon$ or $\frac{\left\|r_{q}\right\|}{1+\|q\|}>\varepsilon$ do begin

Prediktor lépés

$a=-x s$;

$(\Delta x, \Delta s)$ kiszámítása (5) alapján

if $M$ szinguláris then

return $M$ nem $P_{0}$ tulajdonságú;

end if

$\alpha=$ prediktorLepeshossz $(\gamma)$;

if $\alpha<\alpha_{p}^{*}(\kappa)$ then

$\kappa(\Delta x)$ kiszámítása a (3) alapján; 
if $\kappa(\Delta x)$ nem létezik then

return $M$ nem $P_{*}$ tulajdonságú;

\section{end if}

if $\kappa(\Delta x)>\tilde{\kappa}$ then

return $M$ nem $P_{*}(\tilde{\kappa})$ tulajdonságú;

end if

$\kappa=\kappa(\Delta x)$;

$$
\alpha_{c}^{*}(\kappa)=\frac{2 \gamma}{(1+4 \kappa) n+1}
$$

\section{end if}

$$
\begin{aligned}
& x=x+\rho \alpha \Delta x ; \\
& s=s+\rho \alpha \Delta s ; \\
& \mu=\sigma\left(x^{T} s\right) / n ; \\
& r_{q}=M x+q-s ;
\end{aligned}
$$

$$
\begin{aligned}
& \text { Korrektor lépés } \\
& a=\mu e-x s ; \\
& (\Delta x, \Delta s) \text { kiszámítása (5) alapján; } \\
& \text { if } M \text { szinguláris then } \\
& \text { return } M \text { nem } P_{0} \text { tulajdonságú; } \\
& \text { end if } \\
& \text { if }\left(x\left(\alpha_{c}^{*}(\kappa)\right), s\left(\alpha_{c}^{*}(\kappa)\right) \notin D(\gamma)\right. \text { then } \\
& \quad \kappa(\Delta x) \text { kiszámítása a }(3) \text { alapján; } \\
& \text { if } \kappa(\Delta x) \text { nem létezik then } \\
& \quad \text { return } M \text { nem } P_{*} \text { tulajdonságú; } \\
& \quad \text { end if } \\
& \text { if } \kappa(\Delta x)>\tilde{\kappa} \text { then } \\
& \quad \text { return } M \text { nem } P_{*}(\tilde{\kappa}) \text { tulajdonságú; } \\
& \quad \text { end if } \\
& \quad \kappa=\kappa(\Delta x) ; \\
& \quad \alpha_{p}^{*}(\kappa)=\frac{2 \sqrt{(1-\gamma) \gamma}}{(1+4 \kappa) n+2} \\
& \text { end if } \\
& \alpha=k o r r e k t o r L e p e s h o s s z\left(\gamma, \beta, \beta_{\max }\right) ; \\
& x=x+\rho \alpha \Delta x ; \\
& s=s+\rho \alpha \Delta s ; \\
& \mu=\sigma\left(x^{T} s\right) / n ; \\
& r_{q}=M x+q-s ; \\
& \text { end }
\end{aligned}
$$

\section{end if}

END

\subsection{A lépéshossz meghatározása}

Az algoritmus implementációja során a lépéshossz kiszámítására sajátos módszereket adtunk meg.

\subsubsection{A prediktorlépéshossz kiszámítása}

A prediktorlépésben a Potra és Liu [2] által megadott módszerből kiindulva valósítottuk meg az a lépéshossz meghatározását, de figyelembe vettük azt is, hogy a lépéshossz őrizze meg az $x>0, s>0$ feltételeket. A következő függvény szemlélteti ezt: function predictorLepeshossz( $\gamma)$ :

$$
\begin{aligned}
& \alpha_{1}=\min \left\{-\frac{x_{i}}{\Delta x_{i}} \mid \Delta x_{i}<0\right\} ; \\
& \alpha_{2}=\min \left\{-\frac{s_{i}}{\Delta s_{i}} \mid \Delta s_{i}<0\right\} ; \\
& \alpha=\min \left\{\alpha_{1}, \alpha_{2}\right\} ; \\
& u=\frac{x s}{\mu} ; \quad v=\frac{\Delta x \Delta s}{\mu} ; \\
& t=\frac{1-\gamma}{(1+4 \kappa) n+1} ; \\
& \alpha=\min \left\{\alpha, \frac{2}{1+\sqrt{1-4 e^{T} v / n}}\right\} ; \\
& \text { for } i=1 \text { to } n \text { do begin } \\
& \quad b=v_{i}-(1-t) \gamma e^{T} v / n ; \\
& \quad c=u_{i}-(1-t) \gamma ; \\
& \Delta=c^{2}-4 b c ; \\
& \text { if } \Delta>0 \text { and } b \neq 0 \text { then } \\
& \quad \alpha=\min \left\{\alpha, \frac{2\left(u_{i}-(1-t) \gamma\right)}{u_{i}-(1-t) \gamma+\sqrt{\Delta}}\right\} ; \\
& \quad \text { end if } \\
& \text { end } \\
& \text { return } \alpha ; \\
& \text { end }
\end{aligned}
$$

\subsubsection{A korrektorlépéshossz kiszámítása}

A korrektorlépés hosszúságának meghatározására a [2] cikkben javasolt módszertől eltérő megoldást adtunk meg. A függvény meghatározza a maximális lehetséges $\alpha$ lépéshosszt, amely nem sérti az $X, s>0$ feltételt. Ezután a $[0, \alpha]$ intervallumot felosztjuk $\beta$ egyenlő részre, és vizsgáljuk, hogy a részintervallumok végpontjaiban szereplő értékek esetén vett lépéshossz benne van-e a $D(\gamma)$ környezetben. Ha igen, akkor kiszámítjuk az adott értékre vett új $(x, s)$ pont esetén $\mu(\alpha)=\frac{x(\alpha)^{T} s(\alpha)}{n}$ értékét, majd az lesz a végleges lépéshossz, amelyre $\mu(\alpha)$ minimális.

Ha nem találtunk olyan pontot, amely benne van a környezetben, akkor a $\beta$ értékét megduplázzuk, és újból elvégezzük a fenti eljárást. A $\beta$ értékére megadtunk egy $\beta_{\max }$ felső határt, amelyet ha elérünk, hibával megállunk. A módszert a következő függvény segítségével írhatjuk le:

function korrektorLepeshossz $\left(\gamma, \beta, \beta_{\text {max }}\right.$ ):

$$
\begin{aligned}
& \alpha_{1}=\min \left\{-\frac{x_{i}}{\Delta x_{i}} \mid \Delta x_{i}<0\right\} ; \\
& \alpha_{2}=\min \left\{-\frac{s_{i}}{\Delta s_{i}} \mid \Delta s_{i}<0\right\} ; \\
& \alpha=\min \left\{\alpha_{1}, \alpha_{2}\right\} ; \\
& \text { notfound }=\text { true; }
\end{aligned}
$$

while $\beta<\beta_{\max }$ and notfound do begin

for $i=1$ to $n$ do begin 


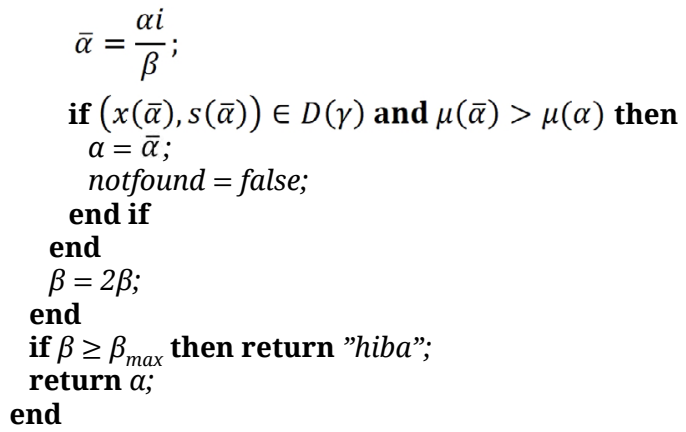

\section{Numerikus eredmények}

A megvalósítás C++ programozási nyelvben, Visual Studio környezetben, Windows operációs rendszer alatt történt, egy 1,9 GHz-es processzorral rendelkező számítógépen. A használt paraméterek: $\rho=0.95, \sigma=0.1, \varepsilon=10^{-5}, \gamma=0.9, \beta=100$, $\beta_{\text {max }}=1000, \tilde{\kappa}=10^{40}$. A kezdeti pontoknak az $x_{0}=e$ és $s_{0}=e$ vektorokat választottuk.

\subsection{Elégséges mátrixok}

A [7] cikkben leírt módszerrel generált elégséges mátrixokra alapozott feladatokra az általunk implementált algoritmus legtöbb 6 iteráció alatt megtalálta a megoldást. Az 1. táblázat az átlagos futási időket tartalmazza (másodpercben) azonos méretű feladatok esetén.

Levonhatjuk a következtést, hogy a feladat méretének a növekedésével a futási idő jelentősen megnövekedett.

\subsection{A Csizmadia-mátrix}

A Csizmadia Zsolt által bevezetett mátrixcsalád esetén elméleti úton bizonyították [8], hogy a mérettel arányosan a maximális $\kappa$ exponenciálisan növekszik. Az általunk kapott lokális $\kappa$ értékek igazolják ezt az elméleti eredményt (lásd a 2. táblázatot).

A kapott к értékek a [9] cikkbeli eredményhez hasonló változást mutatnak a méret függvényében.

1. táblázat. Átlagos futási idők a méret függvényében a [7]-beli feladatokra

\begin{tabular}{|c|c|c|c|}
\hline $\mathbf{n}$ & 10 & 20 & 50 \\
\hline $\mathbf{C P U}$ & 0.1209 & 0.1941 & 0.5876 \\
\hline $\mathbf{n}$ & 100 & 200 & 500 \\
\hline $\mathbf{C P U}$ & 2.0456 & 9.9068 & 131.9007 \\
\hline
\end{tabular}

2. táblázat. A maximális lokális $\kappa$ értékek változása a méret függvényében

\begin{tabular}{|c|c|c|c|}
\hline $\mathbf{n}$ & 10 & 50 & 100 \\
\hline $\mathbf{K}$ & 347.53 & $4.65 \cdot 10^{16}$ & $1.89 \cdot 10^{34}$ \\
\hline
\end{tabular}

\section{Következtetések}

Az [1] publikációban bevezetett prediktor-korrektor GLCP-re mutattuk be saját megvalósításunkat, korrektorlépés esetén egy sajátos lépéshosszszámító módszert bevezetve. Ismertettük az algoritmusra kapott numerikus eredményeket elégséges mátrixhoz kapcsolódó bemenetekre. A Csizmadia Zsolt által bevezetett mátrixok esetén a $\kappa$ változását figyeltük meg a méret függvényében.

\section{Köszönetnyilvánítás}

A szerzők köszönetüket fejezik ki az Erdélyi Múzeum-Egyesületnek a kutatási munkához nyújtott támogatásért.

\section{Szakirodalmi hivatkozások}

[1] Illés T., Nagy M., Terlaky T.: Polynomial Interior Point Algorithms for General Linear Complementarity Problems. Algorithmic Operations Research, 5/1. (2010) 1-12.

[2] Potra F. A., Liu X.: Predictor-Corrector Methods for Sufficient Linear Complementarity Problems in a Wide Neighborhood of the Central Path. Optimization Methods and Software, 20/1. (2005) 145-168. https://doi.org/10.1080/10556780512331318038

[3] Illés T., Nagy M., Terlaky T.: Ep Theorem for Dual Linear Complementarity Problems. Journal of Optimization Theory and Applications, 140. (2009) 233-238. https://doi.org/10.1007/s10957-008-9440-0

[4] Illés T., Nagy M., Terlaky T.: A Polynomial PathFollowing Interior Point Algorithm for General Linear Complementarity Problems. Journal of Global Optimization, 47/3. (2010) 329-342. https://doi.org/10.1007/s10898-008-9348-0

[5] Darvay Zs., Füstös Á.: Numerical Results for the General Linear Complementarity Problem. Müszaki Tudományos Közlemények, 9. (2019) 43-46. https://doi.org/10.33894/mtk-2019.11.07

[6] Kojima M., Megiddo N., Noma T., Yoshise A.: A Unified Approach to Interior Point Algorithms for Linear Complementarity Problems. Springer Verlang, Berlin, 1991.

[7] Illés T., Morapitiye S.: Generating Sufficient Matrices. In: Short Papers of the $8^{\text {th }}$ VOCAL Optimization Conference: Advanced Algorithms held in Esztergom, Hungary. (Szerk.: Friedler F.) Pázmány Péter Katolikus Egyetem, Budapest, 2018. 56-61.

[8] de Klerk E., E.-Nagy M.: On the Complexity of Computing the Handicap of a Sufficient Matrix. Mathematical Programming, 129. (2011) 383-402. https://doi.org/10.1007/s10107-011-0465-Z

[9] Darvay Zs., Illés T., Povh J., Rigó P. R.: Feasible Corrector-Predictor Interior-Point Algorithm for $P_{*}(\kappa)$-Linear Complementarity Problems Based on a New Search Direction. SIAM Journal on Optimization, 30/3. (2020) 2628-2658.

https://doi.org/10.1137/19M1248972 